\title{
Electrocatalytic and pseudocapacitive properties of cobalt (hydro)oxide films on sintered metal fiber filter
}

\author{
Ieva Barauskien $\dot{\mathbf{1}}^{1}$ (D) Eugenijus Valatka ${ }^{1}$
}

Received: 20 May 2017 / Accepted: 29 November 2017/Published online: 5 December 2017

(c) The Author(s) 2017. This article is an open access publication

\begin{abstract}
Cobalt (hydro)oxide films on Bekipor ST 20AL3 sintered metal fiber were formed by electrochemical deposition under galvanostatic conditions using different electrolyte baths (nitrate, acetate and chloride). Cobalt oxide films were prepared via thermal treatment of as-deposited specimens at $673 \mathrm{~K}$. Electroactive surface area of as-deposited and annealed films was estimated using oxidation-reduction system containing ferricyanide/ferrocyanide. Electrocatalytic and pseudocapacitive properties of the prepared films were investigated using $0.1 \mathrm{M} \mathrm{NaOH}$ aqueous solutions. The maximum specific capacitance of $1324 \mathrm{~F} \mathrm{~g}^{-1}$ was observed for $\alpha-\mathrm{Co}(\mathrm{OH})_{2}$ films electrodeposited from nitrate-containing electrolyte. Similarly, the highest electrocatalytic activity and stability in oxygen evolution reaction (OER) was determined to be characteristic for $\mathrm{Co}_{3} \mathrm{O}_{4}$ films derived from nitrate bath.
\end{abstract}

Keywords Cobalt hydroxide - Oxygen evolution reaction . Electroactive surface area $\cdot$ Metal fiber filters $\cdot$ Specific capacitance

\section{Introduction}

Increasing energy demands along with sustainable consumption and environmental concerns require searching for alternative energy sources. Hydrogen, as a clean fuel, is one of the most promising materials to fulfill all these

Ieva Barauskiene

ieva.barauskiene@ktu.lt

1 Department of Physical and Inorganic Chemistry, Kaunas University of Technology, Radvilenụ pl. 19, 50254 Kaunas, Lithuania requirements, especially synthesized during water electrolysis. Oxygen evolution reaction (OER) $2 \mathrm{H}_{2}$ $\mathrm{O} \rightarrow 4 \mathrm{H}^{+}+\mathrm{O}_{2}+4 \mathrm{e}$ (in acid) or $4 \mathrm{OH}^{-} \rightarrow 2 \mathrm{H}_{2} \mathrm{O}+$ $\mathrm{O}_{2}+4 \mathrm{e}$ (in base) is a half reaction of electrochemical water splitting, coupled with hydrogen production. However, these reactions are kinetically sluggish in nature and typically require overpotential of thermodynamically calculated potential for water splitting $(1.23 \mathrm{eV})$ [1-3]; therefore, an effective catalyst is needed. So far $\mathrm{RuO}_{2}$ and $\mathrm{IrO}_{2}$ are the most effective catalysts for OER, but the high price and limited natural sources lead to search for alternative materials. The transition metal-based OER catalysts, especially cobalt- and nickel-containing oxide, hydroxide and oxyhydroxide, are reasonable selection due to their photocatalytic and electrocatalytic activity in OER, good stability and earth abundant nature [4-14]. A spinel-type cobalt oxide $\mathrm{Co}_{3} \mathrm{O}_{4}$, consisting of $\mathrm{Co}^{2+}$ at tetrahedral sites and $\mathrm{Co}^{3+}$ at octahedral sites, exhibits great electrocatalytic activity and stability in alkaline media $[15,16]$.

Cobalt oxide compounds, having a layered structure with large interlayer spacing, show not only high catalytic activity in OER, but also distinguish with great pseudocapacitive properties. Pseudocapacitors store energy by charge transfer between electrode and electrolyte because of the Faradaic reactions, occurring on the surface of active material; capacitance is determined by the electric charge transfer which rate depends on the quantity of active substance and the surface area of transfer [17-20]. Supercapacitors provide much longer cycle life $\left(\sim 10^{6}\right.$ cycles) and shorter period of charge accumulation $(\sim 0.6 \mathrm{~s})$ comparing with electrochemical batteries or fuel cells. The major properties of supercapacitors are cycling life, self-discharge current and efficiency [19]. Ruthenium oxide, activated carbon and conducting polymers are successfully used as active materials in the composition of 
supercapacitors. However, the metal oxides are considered as the most promising electroactive materials [17].

Surface area is one of the most important parameters in the design of electrocatalytic cell or supercapacitors; forming $3 \mathrm{D}$ structure of the active substance on a conductive support increase activity in oxygen evolution reaction and the specific capacitance. For these purposes, $\mathrm{Ti}$ or $\mathrm{Ni}$ meshes are often used as a supports in order to enhance the performance of electroactive materials. Alternatively, sintered metal fiber filter can be less expensive option for the preparation of electrodes. For example, Bekipor STOAL3-type filter is a mechanically and chemically stable composition of chaotically placed thin metal filaments $(d=2-30 \mu \mathrm{m})$, in the form of a panel (thickness $0.51 \mathrm{~mm}$ ) [21]. Small fiber diameter, density and thickness of this mesh enable to increase the active surface area along with good accessibility of deeper filaments and free-flow of the electrolyte solution. However, traditional synthesis methods cannot guarantee the even deposition of each filament without clogging the space between fibers. Thin films with specific composition, morphology and good adhesion between the deposited film and the substrate can be prepared using the electrochemical deposition. The final morphology and texture of the electrodeposited material depend on the electrolyte composition, temperature, electrode potential or current density, duration of electrodeposition process and nature of the electrode substrate [22].

The aim of the present work was to prepare cobalt (hydro)oxide films on Bekipor STOAL3 type metal fiber and to investigate their structure and electrochemical properties. In order to achieve this goal, we tried to solve the following tasks: (1) to determine the optimal conditions for the uniform electrodeposition of cobalt (hydro)oxide films on metal filaments; (2) to estimate the electroactive surface area of the prepared films; (3) to evaluate their pseudocapacitive properties and electrocatalytic activity in oxygen evolution reaction using $\mathrm{NaOH}$ solutions.

\section{Experimental}

\section{Preparation of the films}

Cobalt hydroxide films on stainless steel were prepared by electrochemical deposition using a standard three electrode cell (volume $100 \mathrm{~mL}$ ). Bekipor ST 20AL3 mesh was used as a support. Sintered metal fiber filter (SMFF) Bekipor ST $20 A L 3$ in the form of a panel with thickness of $0.49 \mathrm{~mm}$ was supplied by Bekaert Fibre Technology (Belgium). This material has a porosity of $81 \%$.

All solutions were prepared using doubly distilled water and analytical grade reagents. Cobalt nitrate
$\left(\mathrm{Co}\left(\mathrm{NO}_{3}\right)_{2} \cdot 6 \mathrm{H}_{2} \mathrm{O},>99 \%\right.$ purity, Chempur, Poland), cobalt chloride $\left(\mathrm{CoCl}_{2} \cdot 6 \mathrm{H}_{2} \mathrm{O},>99 \%\right.$ purity, Chempur, Poland), cobalt acetate $\left(\mathrm{Co}\left(\mathrm{CH}_{3} \mathrm{COO}\right)_{2} \cdot 4 \mathrm{H}_{2} \mathrm{O},>97 \%\right.$ purity, Reachim, Russia), potassium nitrate $\left(\mathrm{KNO}_{3}\right.$, purity $>99 \%$, Lachema, Czech Republic) and sodium hydroxide $(\mathrm{NaOH},>98 \%$ purity, Lachema, Czech Republic) were used as received without further purification. Only freshly prepared solutions (initial $\mathrm{pH}$ 3.93-7.05) were used for the deposition. All solutions were not deaerated during the experimental runs. The electrochemical synthesis was carried out at $291 \pm 1 \mathrm{~K}$. The as-deposited samples were thoroughly washed with distilled water and dried to constant weight at room temperature. The electrodeposition process was carried out under galvanostatic conditions. The previously obtained results [23] showed that the most stable films were obtained at $0.5 \mathrm{~mA} / \mathrm{cm}^{2}$. Temperature treatment for all deposited coatings was carried out in $673 \mathrm{~K}$ for $1 \mathrm{~h}$; temperature raising speed was $10 \mathrm{~K} \mathrm{~min}^{-1}$ and after annealing coatings were allowed to cool.

\section{Electrochemical measurements}

The electrochemical measurements were taken by computer-controlled potentiostats/galvanostat Autolab PGSTAT12 (Ecochemie, The Netherlands). The GPES ${ }^{\circledR}$ 4.9 software was used for the collection and treatment of the experimental data. A Pt wire (geometric area about $15 \mathrm{~cm}^{2}$ ) and $\mathrm{Ag}, \mathrm{AgCl} \mid \mathrm{KCl}$ (sat) electrode were used as counter and reference electrodes, respectively. All potentials throughout the paper are referred to $\mathrm{Ag}, \mathrm{AgCl}$ I $\mathrm{KCl}$ (sat) electrode. 0.1 M NaOH (purity $>98 \%$, Lachema, Czech Republic) solution was used as a supporting electrolyte. Potassium ferricyanide (purity $>99 \%$, Reachim, Russia) was used for determination of electroactive surface area of the coatings. The oxidation-reduction system of ferricyanide/ferrocyanide exhibits nearly a reversible electrode reaction without any side reactions. The system can be illustrated by the reversible reaction below [24, 25]:

$\left[\mathrm{Fe}^{3+}(\mathrm{CN})_{6}\right]^{3-}+e^{-} \leftrightarrow\left[\mathrm{Fe}^{2+}(\mathrm{CN})_{6}\right]^{4-}$.

For the evaluation of the specific capacitance of the films, all cyclic scans were repeated at least ten times. As it has been mentioned previously [23], the losses of the specific capacitance were calculated to be around 50-60\% for the first cycle and 1-3\% for all the other cycles for asdeposited coatings. Meanwhile, annealed coatings distinguish with much better stability: the losses of specific capacitance do not exceed $4 \%$. According to these estimations, the anodic charge value of the tenth cycle was only used in calculations. During all experimental runs, the potential of the prepared electrodes was cycled between -0.2 and +0.2 at a scan 


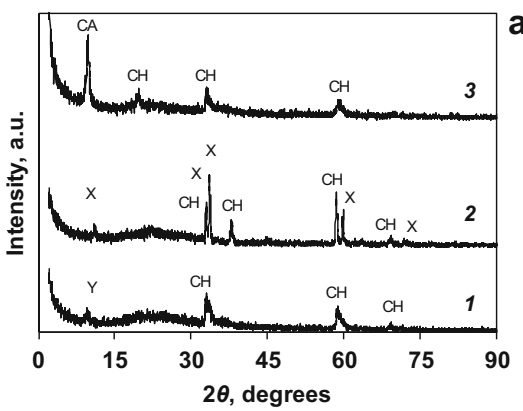

Fig. 1 XRD patterns of as-deposited (a) and annealed at $673 \mathrm{~K}$ (b) cobalt (hydro)oxide films, electrodeposited using different cobalt precursors: 1 cobalt nitrate, 2 cobalt chloride, 3 cobalt acetate.

rate of $20 \mathrm{mV} / \mathrm{s}$. The amounts of the active materials were determined by gravimetric method.

\section{Structural and morphological characterization}

The X-ray powder diffraction (XRD) data were collected with DRON-6 (Bourevestnik Inc., Russia) powder diffractometer with Bragg-Brentano geometry using Nifiltered $\mathrm{Cu} \mathrm{K} \alpha$ radiation and graphite monochromator. The average crystallite size $D_{h k l}$ was calculated from the line broadening using the Scherrer's equation [26]:

$D_{\mathrm{hkl}}=\frac{k \times \lambda}{B_{h k l} \times \cos \theta}$,

where $\lambda$ is the wavelength of the $\mathrm{Cu}-\mathrm{K} \alpha$ radiation, $\theta$ the Bragg diffraction angle, $B_{h k l}$ the full width at the half maximum intensity of the characteristic reflection peak and $\mathrm{k}$ is a constant (the value used in this study was 0.94).

All scanning electron microscopy (SEM) images were acquired using the Hitachi S-4800 scanning electron microscope operating at $2 \mathrm{kV}$ accelerating voltage. Samples were imaged without any conductive film.

\section{Results and discussion}

\section{Structure and morphology of the films}

Previous studies [23] showed that the most stable films are deposited at the current density of $0.5 \mathrm{~mA} / \mathrm{cm}^{2}$. The lamellar structure and composition of $\alpha-\mathrm{Co}(\mathrm{OH})_{2}$ of asdeposited films were confirmed by XRD, FTIR and XPS [23].

The coatings were deposited from electrolyte baths containing three different sources of cobalt (II) ions (nitrate, acetate and chloride). The composition and structure

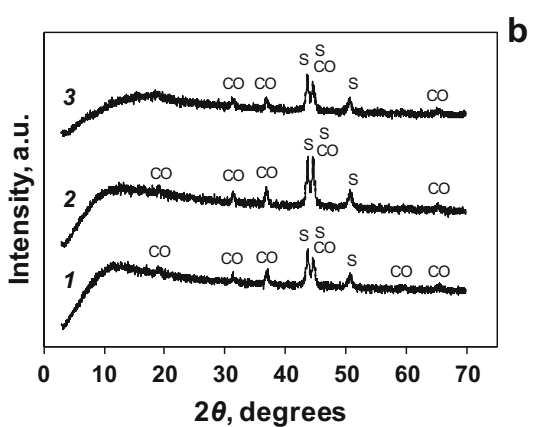

Indexes: $\mathrm{CH}$ cobalt hydroxide, $\mathrm{CO}$ cobalt oxide, $\mathrm{CA}$ cobalt acetate, $X$ potassium cobalt oxide, $Y$ mixed potassium, nitrate and cobalt compound, $S$ substrate (stainless steel)

of the as-deposited (Fig. 1a) and annealed at $673 \mathrm{~K}$ for $1 \mathrm{~h}$ (Fig. 1b) cobalt (hydro)oxide films were investigated using $\mathrm{X}$-ray powder diffraction. XRD analysis of as-deposited coatings indicated patterns characteristic mainly to $\alpha$ cobalt hydroxide $\mathrm{Co}(\mathrm{OH})_{2}$ (d-spacing $0.274,0.268,0.237$, etc., nm.; JCPDF 2-925). However, small quantities of impurities and intercalated ions, which are unavoidable during electrosynthesis, were specific to each electrolyte. Cobalt hydroxide, deposited from cobalt chloride (Fig. 1a, 2 ), turned out to have the highest amount of impurities indicated as potassium cobalt oxide $\mathrm{KCoO}_{2}$, JCPDF 32-769. This side-product gives a green shade to blue $\alpha$ $\mathrm{Co}(\mathrm{OH})_{2}$. XRD analysis of cobalt hydroxide, deposited from nitrate electrolyte (Fig. 1a, 1), indicated a compound of nitrate, cobalt and potassium ions, which intercalated into the structure (peak marked as Y). Cobalt hydroxide, deposited from cobalt acetate, also has impurity, determined as cobalt acetate (Fig. 1a, 3).

The corresponding XRD pattern of thermally treated samples (Fig. 1b) reveals diffraction peaks which can be readily attributed to the cubic phase of $\mathrm{Co}_{3} \mathrm{O}_{4}$ (d-spacing 4.6694, 2.8580, 2.4349, etc., nm.; JCPDF 76-1802) without any impurities left after annealing.

To evaluate the influence of precursors to the morphology of the deposits, crystallite sizes were calculated according to Sherrer's Eq. (1) and the results are given in Table 1 . It can be noticed, that cobalt hydroxide, deposited from nitrate and acetate electrolytes distinguish with almost equally crystallite size, meanwhile cobalt hydroxide crystals, obtained from chloride precursor, are smaller.

SEM images at two magnifications of uncovered Bekipor ST $20 A L 3$ mesh (Fig. 2a) and mesh with cobalt hydroxide deposited for 120 and $300 \mathrm{~s}$ are shown (Fig. 2b-d). Formation of 3D structure of the electrocatalyst with covered filaments and free space between them for electrolyte to flow freely was one of the main 
Table 1 Average crystallite size of cobalt oxide coatings, deposited from different electrolyte baths, calculated according to Sherrer's equation

\begin{tabular}{ll}
\hline Sample & Average crystallite size $(\mathrm{nm})$ \\
\hline $\mathrm{Co}(\mathrm{OH})_{2}$ from acetate & 24.0 \\
$\mathrm{Co}(\mathrm{OH})_{2}$ from nitrate & 25.4 \\
$\mathrm{Co}(\mathrm{OH})_{2}$ from chloride & 18.3 \\
$\mathrm{Co}_{3} \mathrm{O}_{4}$ from acetate & 20.4 \\
$\mathrm{Co}_{3} \mathrm{O}_{4}$ from nitrate & 23.7 \\
$\mathrm{Co}_{3} \mathrm{O}_{4}$ from chloride & 26.6 \\
\hline
\end{tabular}

purposes of this work. Reviewing SEM images, the assumption can be made that deposition time of $120 \mathrm{~s}$ is optimal while longer duration of synthesis reduce active
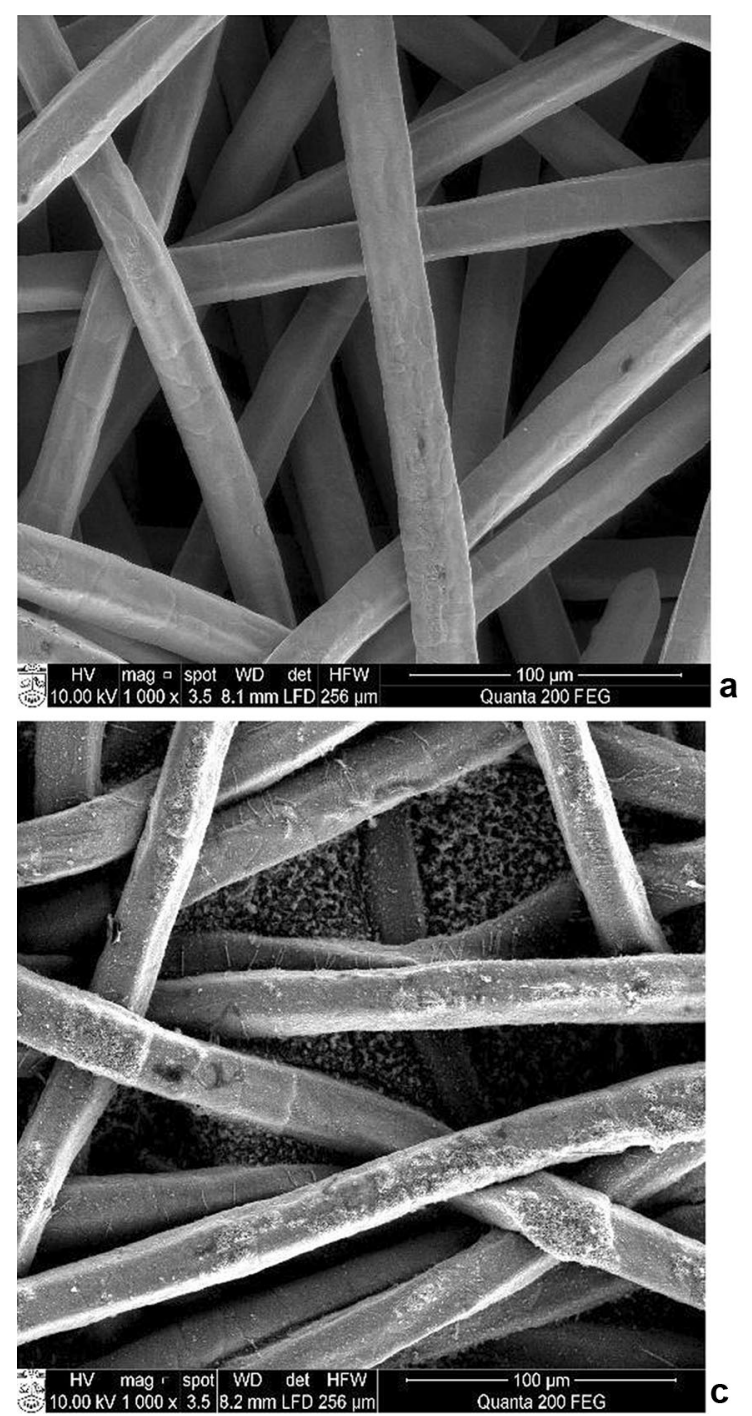

surface area by clogging the space between fibers (Fig. 2c, d).

\section{Capacitive properties}

To evaluate the capacitive characteristics of the films deposited from different electrolytes, the cyclic voltammetry tests were employed. The specific capacitance was calculated using the following formula [17]:

$\mathrm{SC}=\frac{Q}{\Delta E \times m}$

where $Q$ is electric charge in coulombs, $\Delta E$ is a potential range in volts and $m$ is the active substance mass in grams.

Table 2 illustrates the dependence between specific capacitance and mass of cobalt hydroxide. As it can be
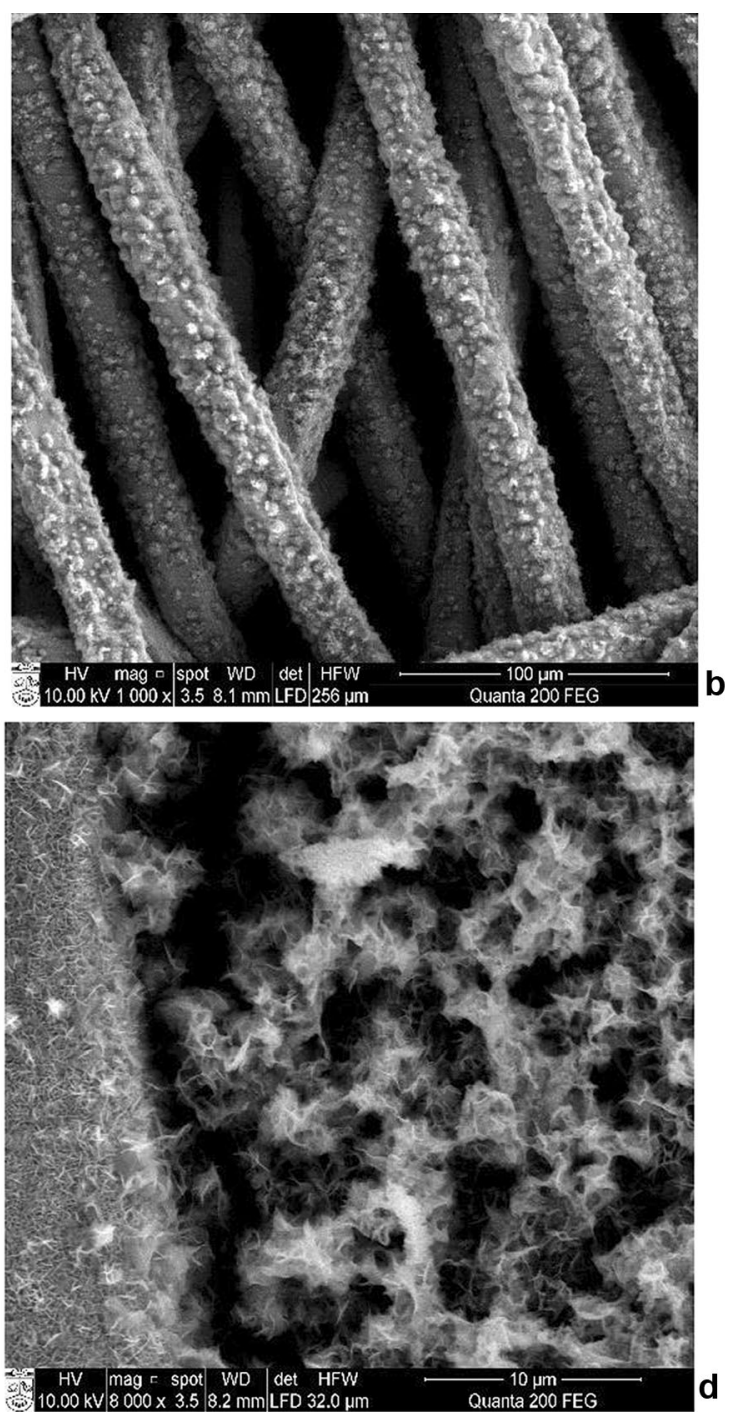

Fig. 2 Representative SEM images of clean Bekipor ST20AL3 stainless steel mesh (a) and as-deposited cobalt hydroxide films at different deposition times (s): b-120, $\mathbf{c}$ and d-300. Magnifications: a, b, $\mathbf{c} \times 1000, \mathbf{d} \times 8000$ 
Table 2 Capacitive characteristics of $\mathrm{Co}(\mathrm{OH})_{2}$ films on metal fiber filter Bekipor ST 20AL3

\begin{tabular}{|c|c|c|c|c|c|c|}
\hline \multirow{3}{*}{$\begin{array}{l}\text { Deposition } \\
\text { time } t,(\mathrm{~s})\end{array}$} & \multicolumn{6}{|c|}{ Electrolyte bath } \\
\hline & \multicolumn{2}{|c|}{$\begin{array}{l}0.05 \mathrm{M} \\
\mathrm{Co}\left(\mathrm{CH}_{3} \mathrm{COO}\right)_{2}\end{array}$} & \multicolumn{2}{|c|}{$\begin{array}{l}0.05 \mathrm{M} \\
\mathrm{Co}\left(\mathrm{NO}_{3}\right)_{2}\end{array}$} & \multicolumn{2}{|c|}{$0.05 \mathrm{M} \mathrm{CoCl}_{2}$} \\
\hline & $\mathrm{m}, \mathrm{mg}$ & $\mathrm{c}, \mathrm{F} \mathrm{g}^{-1}$ & $\mathrm{~m}, \mathrm{mg}$ & $\mathrm{c}, \mathrm{F} \mathrm{g}^{-1}$ & $\mathrm{~m}, \mathrm{mg}$ & $\mathrm{c}, \mathrm{F} \mathrm{g}^{-1}$ \\
\hline 60 & 0.2 & 237 & 0.05 & 822 & 0.3 & 202 \\
\hline 120 & 0.3 & 812 & 0.1 & 1324 & 0.6 & 239 \\
\hline 180 & 0.4 & 842 & 0.5 & 459 & 0.8 & 449 \\
\hline 240 & 0.5 & 965 & 0.9 & 306 & 1.1 & 315 \\
\hline 300 & 0.7 & 689 & 1.1 & 171 & 1.2 & 302 \\
\hline 360 & 0.8 & 154 & 1.2 & 156 & 1.3 & 273 \\
\hline
\end{tabular}

$m$ mass of cobalt hydroxide, $c$ specific capacitance

noticed from the results, the formation of coatings from three sources of cobalt occurs at different growth rates, what affects capacitive behavior as well. The highest specific capacitance $\left(1324 \mathrm{~F} \mathrm{~g} \mathrm{~g}^{-1}\right)$ was reached using electrolyte bath containing cobalt nitrate. The influence of the deposition time to a specific capacitance is clearly observed from the obtained results: synthesis, longer than $300 \mathrm{~s}$, has negative effect on specific capacitance. The variation in the observed values of specific capacitance can be explained in terms of different electroactive surface area, pore structure, presence of adsorbed ions and impurities [27]. For example, XRD analysis revealed that cobalt hydroxide, deposited from chloride bath, has the highest amount of side-product $\mathrm{KCoO}_{2}$, which decrease the capacitive activity of the coating. Furthermore, deposition from cobalt chloride electrolyte allows reaching the highest amount of electroactive materials. This can be related to the diffusional effects, as the mobility of anions in water decreases in the order chloride $>$ nitrate $>$ acetate [28].

Much greater surface area of stainless steel mesh allowed to increase values of specific capacitance, as the highest value of the coating, deposited on AISI304 stainless steel only reached $490 \mathrm{~F} \mathrm{~g}^{-1}$ [29].

The same evaluations of the specific capacitance were performed using annealed cobalt oxide $\mathrm{Co}_{3} \mathrm{O}_{4}$ films. Unfortunately, the relatively low capacitance values were detected $\left(2-8 \mathrm{~F} \mathrm{~g}^{-1}\right)$ and the detrimental effect of temperature treatment to these values was observed. No further measurements of the specific capacitance using $\mathrm{Co}_{3} \mathrm{O}_{4}$ coatings were taken in this work. The fact that $\mathrm{Co}(\mathrm{OH})_{2}$ based materials show much higher specific capacitances than $\mathrm{Co}_{3} \mathrm{O}_{4}$-based materials is pointed out in [30].

\section{Determination of electroactive surface area}

In order to calculate an effective current density, it is important to evaluate electroactive surface area. This is a challenging scientific task and various experimental procedures can be applied as it has been already emphasized by Trasatti and Petrii [31]. The manufacturer of SMFF Bekipor ST 20AL3 does not provide such information; therefore, electroactive surface area was determined by cyclic voltammetry using oxidation-reduction system, containing $2 \mathrm{mM} \mathrm{K}_{3}\left[\mathrm{Fe}(\mathrm{CN})_{6}\right]$ and $0.1 \mathrm{M} \mathrm{KNO}_{3}$. The oxidation-reduction peaks are due to the $\mathrm{Fe}^{3+} / \mathrm{Fe}^{2+}$ redox couple [32]. In this work, calculation of electroactive surface area was based on comparison of current peaks of AISI 304 stainless steel plate with definite surface area and Bekipor ST 20AL3 mesh with geometrically equal surface area. It should be noted that the active surface area of AISI304 is not necessary equal to geometric area but served as a reference material. Each substrate was scanned for ten times to assess the stability of the system and to avoid possible deviations. The values of electroactive surface area were calculated according to the RandlesSevcik equation:

$I_{p}=k \times n^{\frac{3}{2}} \times A \times D^{\frac{1}{2}} \times C \times v^{\frac{1}{2}}$.

In this experiment, $D$ (diffusion coefficient in $\mathrm{cm}^{2}$ ), $n$ (number of electrons transferred per mole of electroactive species), $v$ (potential scan rate, $\mathrm{V} / \mathrm{s}$ ), $k$ (constant) and $C$ (the solution concentration in moles/L) are the same for AISI304 and Bekipor ST 20AL3. The electroactive surface area $A$ is directly proportional to the peak current value $I_{p}$ [32]. Analysis and calculation revealed that average electroactive surface area of uncoated Bekipor ST $20 A L 3$ mesh is $6 \mathrm{~cm}^{2} / \mathrm{cm}^{2}$. This number was used for calculation of effective current density of galvanostatic deposition.

SMFF Bekipor ST 20AL3 distinguishes with mesh structure having chaotically oriented metal filaments. To achieve the highest surface area of an active material, each filament should be coated separately and the space between them should not be clogged. Therefore, it is important to explore the growing process of the coating and to determine the most effective duration of synthesis. Electroactive surface area of as-deposited $\mathrm{Co}(\mathrm{OH})_{2}$ films at different deposition times (Fig. 3a) was measured using the same ferro-ferricyanide oxidation-reduction system. Cobalt oxide $\mathrm{Co}_{3} \mathrm{O}_{4}$, as well-known material for its electrocatalytic activity $[6,8,13,33-35]$ in oxygen evolution reaction, was obtained during heat treatment of as-deposited $\mathrm{Co}(\mathrm{OH})_{2}$ coatings at $673 \mathrm{~K}$ for $1 \mathrm{~h}$. The lamellar structure and composition of tricobalt tetraoxide was confirmed in previous studies [23] by XRD, FTIR and XPS. In order to investigate the effect of temperature treatment to electroactive surface area, the same measurements as with $\mathrm{Co}(\mathrm{OH})_{2}$ were performed (Fig. 3b). The values of electroactive surface area of annealed coatings are presented in 
Fig. 3 Characteristic cyclic voltammograms of as-deposited

(a) and annealed (b) cobalt (hydro)oxide films in

$2 \mathrm{mM} \mathrm{K}_{3}\left[\mathrm{Fe}(\mathrm{CN})_{6}\right]+0.1 \mathrm{M}$

$\mathrm{KNO}_{3}$ electrolyte at different deposition times: 1-60 s,

2-120 s, 3-180 s, 4-240 s, 5-300 s
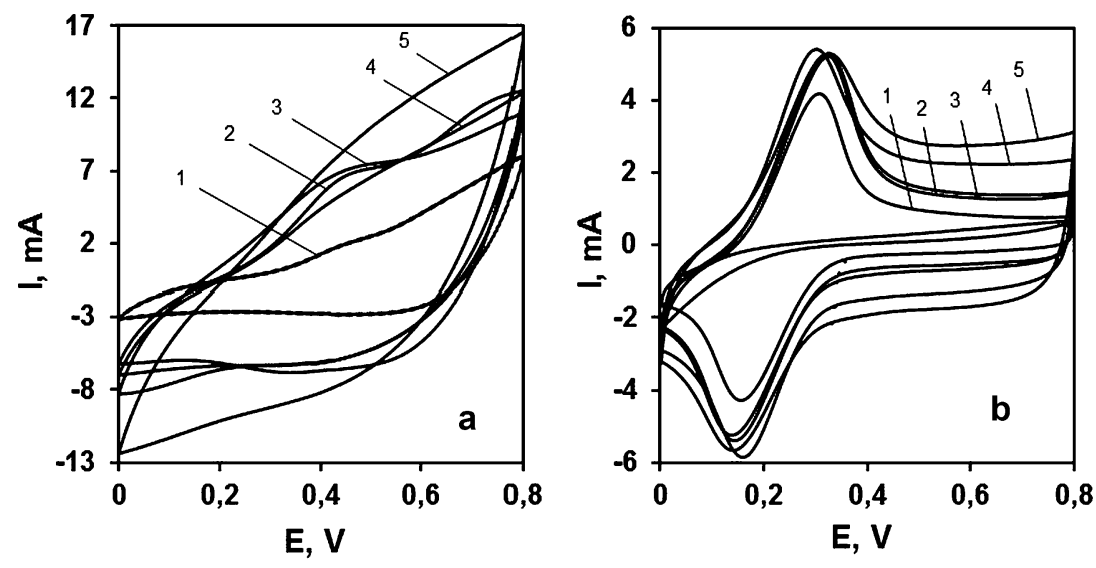

Table 3 Values of electroactive surface area of as-deposited and annealed cobalt (hydro)oxide films

\begin{tabular}{|c|c|c|c|c|c|c|}
\hline \multirow{3}{*}{$\begin{array}{l}\text { Source of cobalt } \\
\text { Deposition time (s) }\end{array}$} & \multicolumn{6}{|c|}{ Electroactive surface area, $\mathrm{cm}^{2} / \mathrm{cm}^{2}$} \\
\hline & \multicolumn{2}{|c|}{ Cobalt nitrate } & \multicolumn{2}{|c|}{ Cobalt acetate } & \multicolumn{2}{|c|}{ Cobalt chloride } \\
\hline & $\mathrm{Co}(\mathrm{OH})_{2}$ & $\mathrm{Co}_{3} \mathrm{O}_{4}$ & $\mathrm{Co}(\mathrm{OH})_{2}$ & $\mathrm{Co}_{3} \mathrm{O}_{4}$ & $\mathrm{Co}(\mathrm{OH})_{2}$ & $\mathrm{Co}_{3} \mathrm{O}_{4}$ \\
\hline 60 & 7.4 & 7.2 & 5.8 & 8.3 & 29.4 & 9.5 \\
\hline 120 & 32.7 & 7.9 & 13.9 & 9.7 & 58.6 & 10.0 \\
\hline 180 & 46.0 & 7.7 & 58 & 14.7 & 57.8 & 10.4 \\
\hline 240 & 44.1 & 8.5 & 64 & 16.5 & 60.6 & 10.7 \\
\hline 300 & 42.2 & 8.9 & 102 & 20.2 & 93.8 & 11.0 \\
\hline
\end{tabular}

Table 3 along with the values of as-deposited coatings. It is seen that the highest alteration in electroactive surface area for all deposited coatings is between deposition times of 60 and $120 \mathrm{~s}$. The lowest values of active surface area are fixed for as-deposited and annealed coatings obtained from cobalt nitrate electrolyte; this regularity can be attributed to the lowest growth of the coatings when using nitrate bath (Table 2). Meanwhile, the values of as-deposited cobalt hydroxide surface area from chloride and acetate solutions are rather similar, as these electrolytes can accumulate more mass of the active material during the same electrodeposition time. The electroactive surface area of all annealed specimens drastically decreases after heat treatment without reference to different precursor used. This reduction of active surface area can be mostly related to the mass loss during annealing, which reaches approximately $57 \%$ according to TG-DSC analysis [36].

\section{Electrocatalytic activity for oxygen evolution reaction}

Linear sweep voltammetry (Fig. 4) was performed to evaluate and compare electrocatalytic behavior in OER of the films deposited from different electrolytes. The estimated values of electroactive surface area (Table 3 ) were used instead of geometric surface area during the calculations of current density. These experimental runs were carried out using films prepared after different electrodeposition times (60-300 s). As shown in Fig. 4, there are small oxidation peaks at around $0.3-0.35 \mathrm{~V}$ for all asdeposited $\mathrm{Co}(\mathrm{OH})_{2}$ films, which can be related to primary oxidation of the film itself $[15,36]$ :

$$
\mathrm{Co}(\mathrm{OH})_{2}+\mathrm{OH}^{-} \leftrightarrow \mathrm{CoOOH}+\mathrm{H}_{2} \mathrm{O}+e^{-}
$$

Scanning to more positive potential area the oxygen evolution starts at $0.6 \mathrm{~V}$ along with the further oxidation of the film:

$\mathrm{CoOOH}+\mathrm{OH}^{-} \leftrightarrow \mathrm{CoO}_{2}+\mathrm{H}_{2} \mathrm{O}+\mathrm{e}^{-}$

The films deposited from cobalt nitrate and cobalt acetate shows the highest electrocatalytic activity. The electrocatalytic activity of the coatings synthesized from cobalt chloride is relatively low. These variations can be related to the different amount of impurities during electrodeposition, confirmed by XRD analysis (Fig. 1). As it was mentioned before, cobalt hydroxide, deposited from chloride electrolyte, has a considerable quantity of side-product $\mathrm{KCoO}_{2}$, which negatively affect the activity of the active material in both capacitive and electrocatalytic applications and gives a green shade to blue $\alpha-\mathrm{Co}(\mathrm{OH})_{2}$. Meanwhile, as-deposited coatings from 
Fig. 4 Linear sweep voltammetry of $\mathrm{Co}(\mathrm{OH})_{2}$ films deposited from nitrate (a), acetate (b) and chloride (c) bath Deposition times: 1-60 s, 2-120 s, 3-180 s, 4-240 s, 5-300 s. $0.1 \mathrm{M} \mathrm{NaOH}$ supporting electrolyte
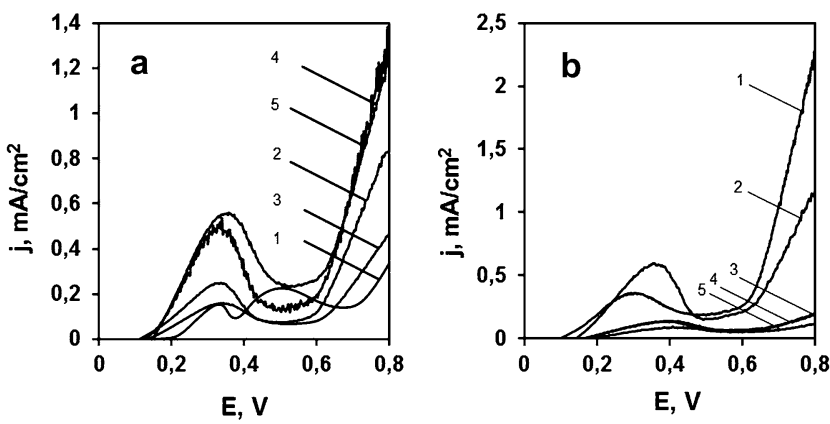

nitrate and acetate solutions are much less impure and retain their blue color.

Similarly, the plots of linear sweep voltammetry of annealed films consisting of $\mathrm{Co}_{3} \mathrm{O}_{4}$ are shown in Fig. 5. In all linear sweep voltammetry plots, the redox peaks at around $0.58-0.65 \mathrm{~V}$ are observed, which correspond to the change between different cobalt oxidation states according to the following reactions $[9,37,38]$ :

$$
\begin{aligned}
& \mathrm{Co}_{3} \mathrm{O}_{4}+\mathrm{H}_{2} \mathrm{O}+\mathrm{OH}^{-} \rightarrow 3 \mathrm{CoOOH}+e^{-} \\
& \mathrm{CoOOH}+\mathrm{OH}^{-} \rightarrow \mathrm{CoO}_{2}+\mathrm{H}_{2} \mathrm{O}+e^{-}
\end{aligned}
$$

The films deposited from cobalt nitrate electrolyte distinguish as the most electrochemically active in oxygen evolution reaction while cobalt oxide obtained from cobalt acetate and cobalt chloride show lower activity. This drop of current density for coatings from acetate and chloride precursors can also be related to significantly higher amount of impurities comparing with nitrate precursor. As shown in Fig. 5, the considerable peaks at $0.5-0.7 \mathrm{~V}$ prove the occurring oxidation of the film, deposited from acetate and chloride electrolytes, while nitrate precursor allows to obtain better purity of cobalt oxide.

Due to the complexity of the OER occurring on the surface of metal oxides, the exact interpretation of the observed variations in electrocatalytic activity of the prepared samples is almost impossible. As it has been pointed out by Doyle and Lyons [1], metal oxides are extremely complex experimental system and their electrocatalytic activity is highly dependent on a multitude of parameters, such as the electronic structure at the surface and in the bulk, morphology and material preparation history. A special attention should be paid to the electroconductivity of the films if the OER is to proceed at a practical rate. The electroconductive properties are highly influenced by the presence of dopants, impurities, film thickness and other factors. In our case, the variations in electrocatalytic activity of cobalt (hydro)oxides can be partly related to the different amount of impurities incorporated during electrodeposition. As it was confirmed by XRD analysis (Fig. 1), cobalt hydroxide, deposited from chloride electrolyte, has a considerable quantity of side-product $\mathrm{KCoO}_{2}$, which can negatively affect the activity of the active material in both capacitive and electrocatalytic applications. On the other hand, the heat treatment improved the electrocatalytic activity of the films tend to become more compact and pure.

In order to investigate the electrochemical behavior of $\mathrm{Co}_{3} \mathrm{O}_{4}$ films in oxygen evolution reaction, controlled potential electrolysis was conducted in $0.1 \mathrm{M} \mathrm{NaOH}$ solution at various applied potentials (Fig. 6a). The electrolyte solution was continuously stirred and after each measurement the electrode was allowed to reach its steadystate potential. The collected current-potential data were used to construct Tafel plot (Fig. 6b). It is well known that the Tafel equation has a fundamental importance in electrochemical kinetics and the slope $b$ is an indicative parameter of the electrode reaction mechanism [39].

Only $\mathrm{Co}_{3} \mathrm{O}_{4}$ films electrodeposited using nitrate bath were used in the experiments due to their superior activity
Fig. 5 Linear sweep voltammetry of $\mathrm{Co}_{3} \mathrm{O}_{4}$ films deposited from nitrate (a), acetate (b) and chloride (c) bath. Deposition times: 1-60 s, 2-120 s, 3-180 s, 4-240 s, 5-300 s. $0.1 \mathrm{M} \mathrm{NaOH}$ supporting electrolyte
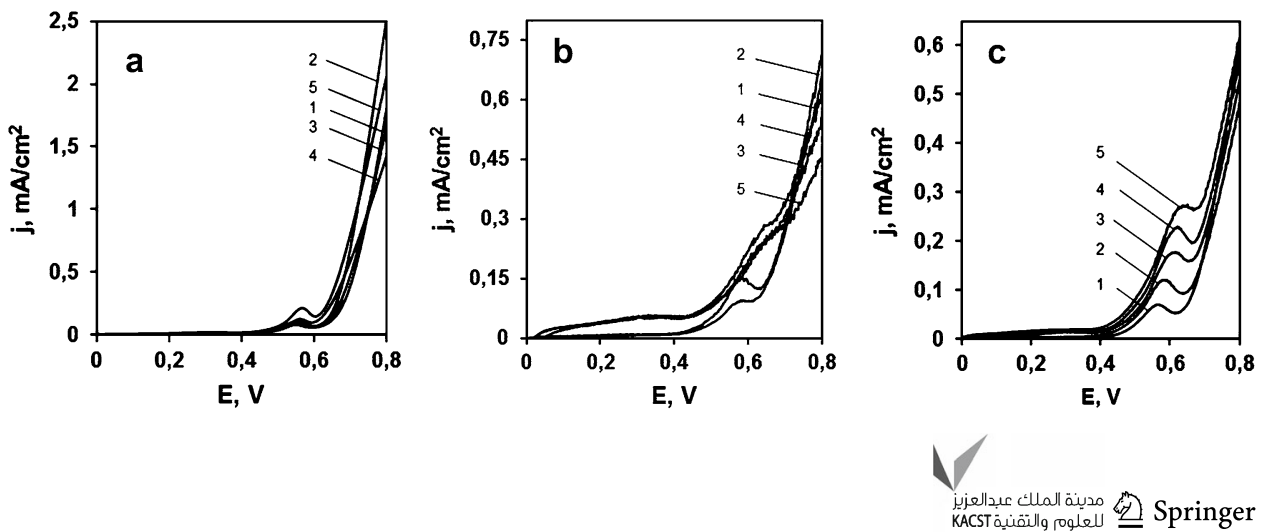
Fig. 6 Characteristic voltamperograms (a) and Tafel plot (b) for $\mathrm{Co}_{3} \mathrm{O}_{4}$ films deposited from cobalt nitrate. $0.1 \mathrm{M} \mathrm{NaOH}$ supporting electrolyte
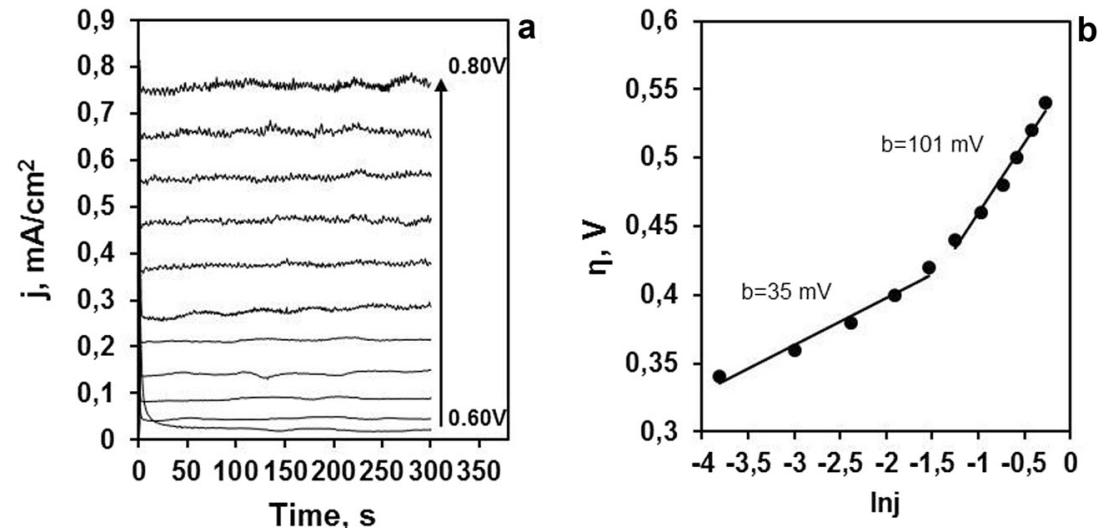

and stability. The overpotential $\eta$ was calculated according to this equation:

$\eta=E_{\text {appl }}-0.26$,

where $E_{\text {appl }}$ is the applied potential $(V)$ measured against $\mathrm{Ag}, \mathrm{AgCl} \mid \mathrm{KCl}_{\text {(sat) }}$ reference electrode, 0.26 is the value of the equilibrium potential against $\mathrm{Ag}, \mathrm{AgCl} \mid \mathrm{KCl}_{\text {(sat) }}$ reference electrode for water oxidation at $\mathrm{pH} 13$.

Figure $6 \mathrm{~b}$ presents the dependence of the overpotential as a function of logarithm of current density for $\mathrm{Co}_{3} \mathrm{O}_{4}$ electrode. An abrupt change of Tafel slope from 35 to $101 \mathrm{mV} /$ decade is observed at overpotential values higher than $0.45 \mathrm{~V}$. The switch of Tafel slope can be considered as an indication of the change of reaction mechanism, for example, the rate-determining step under changed reaction conditions. A smaller Tafel slope suggests that the ratedetermining step is at the ending part of the multiple electron transfer reaction [39]. The obtained results show that $\mathrm{Co}_{3} \mathrm{O}_{4}$ films on sintered metal fiber can be assessed as highly effective and stable electrode for OER, the activity being very similar to those obtained by other authors using nanocomposites [40, 41] or metal-doped structures $[2,12,42-46]$.

\section{Conclusions}

In this work, various cobalt (hydro)oxide films were synthesized by means of galvanostatic electrodeposition using three different electrolytes as the sources of cobalt ions (nitrate, acetate and chloride). Sintered metal fiber was used as a support to form a 3D structure in order to increase specific surface area.

XRD analysis revealed that the as-deposited films consist mainly of $\alpha$-cobalt hydroxide. The presence of some intercalated ions and impurities was identified too. The annealing at $673 \mathrm{~K}$ for $1 \mathrm{~h}$ leads to the formation of pure $\mathrm{Co}_{3} \mathrm{O}_{4}$. It was determined that the electrodeposition time should be shorter than $120 \mathrm{~s}$ in order to obtain uniform distribution of cobalt hydroxide films on the filaments of metal fiber. The electrochemical measurements confirmed that the electrocatalytic and capacitive properties are highly dependent on film preparation conditions. The highest value of specific capacitance $(1324 \mathrm{~F} / \mathrm{g})$ was determined for cobalt hydroxide films electrodeposited using nitrate-containing bath. The results of linear sweep voltammetry and controlled potential electrolysis showed that the highest electrocatalytic activity and stability in oxygen evolution reaction (OER) is characteristic for $\mathrm{Co}_{3} \mathrm{O}_{4}$ films derived from nitrate bath. For these films, the Tafel slope was calculated to be $35 \mathrm{mV} /$ decade at the overpotentials lower than $0.45 \mathrm{~V}$. The obtained results show that the cobalt (hydro)oxide supported on sintered metal fiber present a promising electrode configuration for energy-related applications.

Open Access This article is distributed under the terms of the Creative Commons Attribution 4.0 International License (http:// creativecommons.org/licenses/by/4.0/), which permits unrestricted use, distribution, and reproduction in any medium, provided you give appropriate credit to the original author(s) and the source, provide a link to the Creative Commons license, and indicate if changes were made.

\section{References}

1. Doyle, R.L., Lyons, M.E.G.: The oxygen evolution reaction: mechanistic concepts and catalyst design. In: Gimenez, S., Bisquert, J. (eds.) Photoelectrochemical solar fuel production, pp. 41-104. Springer, Switzerland (2016)

2. Bikkarolla, S.K., Papakonstantinou, P.: $\mathrm{CuCo} 2 \mathrm{O} 4$ nanoparticles on nitrogenated graphene as highly efficient oxygen evolution catalyst. J. Power Sources 281, 243-251 (2015)

3. Jiang, J., Zhang, A., Li, L., Ai, L.: Nickel-cobalt layered double hydroxide nanosheets as high-performance electrocatalyst for oxygen evolution reaction. J. Power Sources 278, 445-451 (2015)

4. Cheng, Q., Tang, J., Zhang, H., Qin, L.: Vertically aligned cobalt hydroxide nano-flake coated electro-etched carbon fiber cloth electrodes for supercapacitors. Chem. Phys. Lett. 616-617, 35-39 (2014) 
5. Fernando, A.: Reaction pathways for water oxidation to molecular oxygen mediated by model cobalt oxide dimer and cubane catalysts. J. Phys. Chem. C 119, 11072-11085 (2015)

6. Hutchings, G.S., Zhang, Y., Li, J., Yonemoto, B.T., Zhou, X., Zhu, K., Jiao, F.: In situ formation of cobalt oxide nanocubanes as efficient oxygen evolution catalysts. J. Am. Chem. Soc. 137, 4223-4229 (2015)

7. Kazemi, S.H., Asghari, A.: Electrochemical fabrication of $\mathrm{Co}(\mathrm{OH})(2)$ nanostructures on electro-etched carbon fibers: characterization and its supercapacitive behavior. Mater. Lett. 142, 156-159 (2015)

8. Menezes, P.W., Indra, A., Gonzalez-Flores, D., Sahraie, N.R., Zaharieva, I., Schwarze, M., Strasser, P., Dau, H., Driess, M.: High-performance oxygen redox catalysis with multifunctional cobalt oxide nanochains: morphology-dependent activity. Acs Catal. 5, 2017-2027 (2015)

9. Qorbani, M., Naseri, N., Moshfegh, A.Z.: Hierarchical Co3O4/ $\mathrm{Co}(\mathrm{OH})(2)$ nanoflakes as a supercapacitor electrode: experimental and semi-empirical model. Acs Appl. Mater. Inter. 7, 11172-11179 (2015)

10. Ahn, H.S., Yano, J., Tilley, T.D.: Water oxidation by cobalt centers on various oxide surfaces: the effects of oxide surface acidity and oxygen atom affinity on catalysis. Acs Catal. 5, 2573-2576 (2015)

11. He, F., Liu, K., Zhong, J., Zhang, S., Huang, Q., Chen, C.: One dimensional nickel oxide-decorated cobalt oxide (Co3O4) composites for high-performance supercapacitors. J. Electroanal. Chem. 749, 89-95 (2015)

12. Jin, H., Wang, J., Su, D., Wei, Z., Pang, Z., Wang, Y.: In situ cobalt-cobalt oxide/N-doped carbon hybrids as superior bifunctional electrocatalysts for hydrogen and oxygen evolution. J. Am. Chem. Soc. 137, 2688-2694 (2015)

13. Raoof, J.B., Chekin, F., Ehsani, V.: Cobalt oxide nanoparticlemodified carbon nanotubes as an electrocatalysts for electrocatalytic evolution of oxygen gas. B. Mater. Sci. 38, 135-140 (2015)

14. Wang, Z., Tang, L., Zhang, Y., Zhan, S., Ye, J.: Electrochemicaldriven water splitting catalyzed by a water-soluble cobalt(II) complex supported by $\mathrm{N}, \mathrm{N}^{\prime}$-bis(2'-pyridinecarboxamide)-1,2benzene with high turnover frequency. J. Power Sources 287, 50-57 (2015)

15. Ghanem, M.A., Al-Mayouf, A.M., Arunachalam, P., Abiti, T.: Mesoporous cobalt hydroxide prepared using liquid crystal template for efficient oxygen evolution in alkaline media. Electrochim. Acta 207, 177-186 (2016)

16. Elumeeva, K., Masa, J., Sierau, J., Tietz, F., Muhler, M., Schuhmann, W.: Perovskite-based bifunctional electrocatalysts for oxygen evolution and oxygen reduction in alkaline electrolytes. Electrochim. Acta 208, 25-32 (2016)

17. Gupta, V., Kusahara, T., Toyama, H., Gupta, S., Miura, N.: Potentiostatically deposited nanostructured $\alpha-\mathrm{Co}(\mathrm{OH}) 2$ : a high performance electrode material for redox-capacitors. Electrochem. Commun. 9, 2315-2319 (2007)

18. Chen, H., Cong, T.N., Yang, W., Tan, C., Li, Y., Ding, Y.: Progress in electrical energy storage system: a critical review. Prog. Nat. Sci. 19, 291-312 (2009)

19. Lokhande, C.D., Dubal, D.P., Joo, O.S.: Metal oxide thin film based supercapacitors. Curr. Appl. Phys. 11, 255-270 (2011)

20. Yuan, C., Zhang, X., Gao, B., Li, J.: Synthesis and electrochemical capacitance of mesoporous $\mathrm{Co}(\mathrm{OH}) 2$. Mater. Chem. Phys. 101, 148-152 (2007)

21. Yuranov, I., Kiwi-Minsker, L., Renken, A.: Structured combustion catalysts based on sintered metal fibre filters. Appl. Catal. B-Environ. 43, 217-227 (2003)
22. Therese, G.H.A., Vishnu Kamath, P.: Electrochemical synthesis of metal oxides and hydroxides. Chem. Mater. 12, 1195-1204 (2000)

23. Barauskiene, I., Valatka, E.: Synthesis, structure and capacitive properties of cobalt hydroxide films on stainless steel substrates. Cent. Eur. J. Chem. 12, 1206-1211 (2014)

24. Baciu, A., Remes, A., Ilinoiu, E., Manea, F., Picken, S.J., Schoonman, J.: Carbon nanotubes composite for environmentally friendly sensing. Environ. Eng. Manag. J. 11, 239-246 (2012)

25. Fotouhi, L., Fatollahzadeh, M., Heravi, M.M.: Electrochemical behavior and voltammetric determination of sulfaguanidine at a glassy carbon electrode modified with a multi-walled carbon nanotube. Int. J. Electrochem. Sc. 7, 3919-3928 (2012)

26. Azaroff, L.V.: Elements of X-ray crystallography. Wiley, New York (1968)

27. Shi, F., Wang, X., Gu, C., Tu, J.: Metal oxide/hydroxide-based materials for supercapacitors. RSC Adv. 4, 41910-41921 (2014)

28. Cussler, E.L.: Diffusion: mass transfer in fluid systems. Cambridge University Press, Cambridge (2009)

29. Barauskiene, I.: Kobalto oksidiniụ dangụ sintezé, struktūra ir elektrocheminès savybès. Kaunas MSc thesis (in Lithuanian) (2012).

30. Wang, G., Zhang, L., Zhang, J.: A review of electrode materials for electrochemical supercapacitors. Chem. Soc. Rev. 41, 797-828 (2012)

31. Trasatti, S., Petrii, O.A.: Real surface area measurements in electrochemistry. Pure Appl. Chem. 63, 711-734 (1991)

32. Zhang, J., Gao, L.: Synthesis of highly dispersed platinum nanoparticles on multiwalled carbon nanotubes and their electrocatalytic activity toward hydrogen peroxide. J. Alloy. Compd. 505, 604-608 (2010)

33. Liu, Y., Han, G., Li, X., Dong, B., Shang, X., Hu, W., Chai, Y., Liu, Y., Liu, C.: A facile synthesis of reduced Co3O4 nanoparticles with enhanced electrocatalytic activity for oxygen evolution. Int. J. Hydrogen Energ. 41, 12976-12982 (2016)

34. Yu, J., Chen, G., Sunarso, J., Zhu, Y., Ran, R., Zhu, Z., Zhou, W., Shao, Z.: Cobalt oxide and cobalt-graphitic carbon core-shell based catalysts with remarkably high oxygen reduction reaction activity. Adv. Sci. 3, 1600060 (2016)

35. Zhang, L., Li, H., Li, K., Li, L., Wei, J., Feng, L., Fu, Q.: Morphology-controlled fabrication of $\mathrm{Co} 3 \mathrm{O} 4$ nanostructures and their comparative catalytic activity for oxygen evolution reaction. J. Alloy. Compd. 680, 146-154 (2016)

36. Kelpsaite, I., Baltrusaitis, J., Valatka, E.: Electrochemical deposition of porous cobalt oxide films on AISI 304 type steel. Mater. Sci. Medzg. 17, 236-243 (2011)

37. Chen, Z., Chen, Y., Zuo, C., Zhou, S., Xiao, A.G., Pan, A.X.: Hydrothermal synthesis of porous $\mathrm{Co}(\mathrm{OH}) 2$ nanoflake array film and its supercapacitor application. B. Mater. Sci. 36, 239-244 (2013)

38. Spataru, N., Terashima, C., Tokuhiro, K., Sutanto, I., Tryk, D.A., Park, S.M., Fujishima, A.: Electrochemical behavior of cobalt oxide films deposited at conductive diamond electrodes. J. Electrochem. Soc. 150, E337-E341 (2003)

39. Suen, N.T., Hung, S.F., Quan, Q., Zhang, N., Xu, Y.J., Chen, H.M.: Electrocatalysis for the oxygen evolution reaction: recent development and future perspectives. Chem. Soc. Rev. 46, 337-365 (2017)

40. Zhang, Y., Ding, F., Deng, C., Zhen, S., Li, X., Xue, Y., Yan, Y., Sun, K.: Crystal plane-dependent electrocatalytic activity of $\mathrm{Co} 3 \mathrm{O} 4$ toward oxygen evolution reaction. Catal. Commun. 67, 78-82 (2015)

41. Ramsundar, R.M., Debgupta, J., Pillai, V.K., Joy, P.A.: Co3O4 nanorods-efficient non-noble metal electrocatalyst for oxygen evolution at neutral pH. Electrocatalysis 6, 331-340 (2015) 
42. Ju, H., Li, Z., Xu, Y.: Electro-catalytic activity of Ni-Co-based catalysts for oxygen evolution reaction. Mater. Res. Bull. 64, 171-174 (2015)

43. Du, J., Chen, C., Cheng, F., Chen, J.: Rapid synthesis and efficient electrocatalytic oxygen reduction/evolution reaction of CoMn2O4 nanodots supported on graphene. Inorg. Chem. 54, 5467-5474 (2015)

44. Cady, C.W., Gardner, G., Maron, Z.O., Retuerto, M., Go, Y.B., Segan, S., Greenblat, M., Dismukes, G.C.: Tuning the electrocatalytic water oxidation properties of $\mathrm{AB}(2) \mathrm{O}(4)$ spinel nanocrystals: $\mathrm{A}(\mathrm{Li}, \mathrm{Mg}, \mathrm{Zn})$ and $\mathrm{B}(\mathrm{Mn}, \mathrm{Co})$ site variants of LiMn2O4. Acs Catal. 5, 3403-3410 (2015)

45. Hu, H., Guan, B., Xia, B., Lou, X.W.: Designed formation of $\mathrm{Co} 3 \mathrm{O} 4 / \mathrm{NiCo} 2 \mathrm{O} 4$ double-shelled nanocages with enhanced pseudocapacitive and electrocatalytic properties. J. Am. Chem. Soc. 137, 5590-5595 (2015)

46. Jang, D.M., Kwak, I.H., Kwon, E.L., Jung, C.S., Im, H.S., Park, K., Park, J.: Transition-metal doping of oxide nanocrystals for enhanced catalytic oxygen evolution. J. Phys. Chem. C 119, 1921-1927 (2015)

\section{Publisher's Note}

Springer Nature remains neutral with regard to jurisdictional claims in published maps and institutional affiliations. 